\title{
Fett- und Kohlenhydratverzehr beeinflussen die innere Uhr des Menschen
}

Unsere innere Uhr steuert die Ausschüttung von Hormonen sowie Stoffwechselvorgänge und Körperfunktionen, die einem annähernd 24-stündigen, also circadianen Rhythmus, unterliegen. So genannte Zeitgeber-Gene regulieren dabei den Takt der Uhr und steuern gleichzeitig durch rhythmisch verknüpfte Stimulations- und Hemmzyklen ihre eigene Synthese. Darüber hinaus beeinflussen aber auch Umweltreize wie das Tageslicht die Aktivität dieser Gene. Untersuchungen lassen zudem annehmen, dass auch die Energiemenge, die wir über die Nahrung aufnehmen sowie das Körpergewicht eine Rolle für die circadiane Rhythmik spielen. Inwieweit die Nährstoffzusammensetzung unseres Essens ebenso Einfluss nimmt, ist bislang nur wenig erforscht.

Daher führten die Wissenschaftler unter Führung des Mediziners und Endokrinologen Andreas F. H. Pfeiffer eine Ernährungsstudie mit eineiigen und zweieiigen Zwillingspaaren durch. Zunächst mussten alle Studienteilnehmer 6 Wochen lang eine kohlenhydratbetonte Diät einhalten. Der Kohlenhydratanteil lag dabei bei 55, der Eiweißanteil bei 15 und der Fettanteil bei 30\% der Gesamtenergiezufuhr. Danach erhielten die Teilnehmer für weitere 6 Wochen eine fettreiche Kost, wobei die Forscher den Anteil der Kohlenhydrate auf $40 \%$ senkten und gleichzeitig den Fettanteil von 30 auf $45 \%$ erhöhten, um

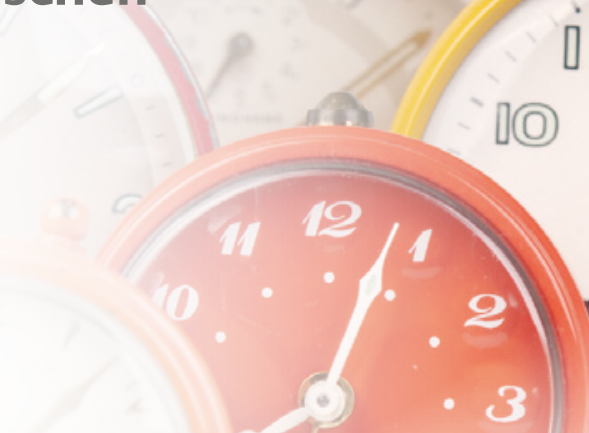

eine gleichbleibende Energieversorgung zu gewährleisten. „Diese isokalorische Ernährung war wichtig, da Unter- oder Überernährung selbst eine starke Stoff-

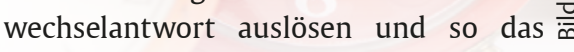
Untersuchungsergebnis verfälschen können“, erklärt Pfeiffer.

Wie die Wissenschaftler anhand von Blutzellanalysen feststellten, veränderte die Ernährungsumstellung innerhalb von 7 Tagen die Aktivitätsmuster von 4 zentralen Zeitgeber-Genen. „Besonders bei eineiigen Zwillingen waren die Aktivitätsmuster auffallend ähnlich. Wir gehen daher davon aus, dass die Art und Weise erblich vorherbestimmt ist, wie das Zeitgeber-Gen-System auf unterschiedliche Nahrungskomponenten reagiert“, sagt Olga Pivovarova, Erstautorin der Studie. Die im Tagesverlauf veränderte Aktivität der Zeitgeber-Gene war dabei eng mit Modulationen im Fett- und Energiestoffwechsel verbunden. Ebenso änderte sich das Aktivitätsmuster bestimmter Gene, die für Entzündungsreaktionen eine Rolle spielen. Die beobachteten Veränderungen waren jedoch nicht nur auf die Gene
\& beschränkt, auch die Tagesrhythmik der Cortisol-Ausschüttung, die vom Gehirn über die Hirnanhangsdrüse gesteuert wird, war verschoben.

Fazit

„Zusammenfassend ist zu sagen, dass die Art der Ernährung sich nicht unerheblich auf unsere innere Uhr auswirkt. Wie unsere Ergebnisse darüber hinaus bestätigen, besteht ein enges Wechselspiel zwischen den circadianen biologischen Rhythmen und den Stoffwechselwegen, die daran beteiligt sind, den Energiestoffwechsel und auch unser Immunsystem an das Nahrungsangebot anzupassen“, so Pfeiffer. „Wenn es durch weitere Studien gelingt, die Mechanismen, die diesen Zusammenhängen zugrunde liegen, noch besser zu verstehen, wird es vielleicht zukünftig möglich sein, konkretere Ernährungsempfehlungen zu geben, die besser auf die innere Uhr und individuellen Bedürfnisse eines Menschen abgestimmt sind.“

Pressemitteilung Deutsches Institut für Ernährungsforschung Potsdam-Rehbrücke vom 13.4.2015 